\title{
AVALIAÇÃO DAS IDADES K/Ar DOS MACIÇOS ALCALINOS DO BRASIL SUL- ORIENTAL E PARAGUAI ORIENTAL
}

\author{
H.H.G.J.Ulbrich ${ }^{1}$ \\ G.M.Garda ${ }^{2}$ \\ M.N.C.Ulbrich ${ }^{1}$
}

As "províncias alcalinas" localizadas ao longo da borda da Bacia do Paraná (ULBRICH \& GOMES, 1981; ALMEIDA, 1983) constituem algumas das mais notáveis manifestações alcalinas do mundo. Têm sido motivo de estudo desde o século passado, sendo que algumas ocorrências tornaram-se as localidades-tipo de rochas alcalinas mundialmente reconhecidas, como, por exemplo, o tinguaíto (Tinguá-RJ) e o bebedourito (Bebedouro-SP).

Nas décadas de 50 e 60 , os trabalhos tomaram impulso, e de grande importância para o melhor conhecimento destas ocorrências foram os trabalhos geocronológicos que se iniciaram com as datações pioneiras de AMARAL et al. (1967). Uma compilação das idades obtidas foi realizada por SONOKI \& GARDA (1988), onde também foram incluídos os dados experimentais das citações bibliográficas. Este trabalho e outros que o sucederam (e.g. BROTZU et al., 1989; RICCOMINI et al., 1990) serviram de base para a presente avaliação.

As idades registradas (num total de mais de $\mathbf{2 0 0}$ determinações pelo método $\mathrm{K} / \mathrm{Ar}$, além de algumas isócronas obtidas com o método $\mathrm{Rb} / \mathrm{Sr}$ ) ensejaram interpretações das mais variadas quanto à gênese das ocorrências alcalinas. Se estas forem representadas num histograma, obter-se-á um gráfico bastante contínuo, com poucas interrupções, para um intervalo desde $270 \mathrm{Ma}$ até $25 \mathrm{Ma}$ e que mostra duas modas mais marcantes, com medianas posicionadas ao redor de 80 e 130 Ma (ULBRICH \& GOMES, 1981). Estes resultados

\footnotetext{
Departamento de Mineralogia e Petrologia, Instituto de Geociências/USP, São Paulo.

${ }^{2}$ Pós-graduação, Instituto de Geociências/USP, São Paulo.
} 
levariam a crer que uma atividade magmática alcalina supostamente contínua, com poucos intervalos de tranqülidade, ter-se-ia estendido por um intervalo da ordem de $250 \mathrm{Ma}$.

Chama a atenção, também, o período extremamente longo de colocação de vários maciços. Foram registradas, em Poços de Caldas, idades mais antigas da ordem de 89 Ma e mais recentes ao redor de $54 \mathrm{Ma}$, que definiriam um suposto período de erupção de 35 Ma. Para Jacupiranga ter-se-ia um intervalo de $227 \mathrm{Ma}$ (desde 273 a $46 \mathrm{Ma}$ ). O pequeno maciço de Banhadão (cerca de $12 \mathrm{~km}^{2}$ ) teria demorado $29 \mathrm{Ma}$ (de 127 a $98 \mathrm{Ma}$ ) para se colocar.

Estes enormes períodos de atividade magmática chocam-se com os dados conhecidos para maciços vulcânicos mais recentes. Os vulcões das Ilthas do Havaí, por exemplo, formaram-se em intervalos não superiores a 1 ou $2 \mathrm{Ma}$, podendo ser de apenas 100.000 anos (e.g. SHAW et al., 1980). A natureza do magmatismo é diferente em ambos os casos (alcalina vs. basáltica), mas, mesmo assim, o intervalo suposto para a colocação das rochas alcalinas parece exagerado. Por este e outros motivos de natureza geológica e geotectônica, foram propostos períodos de atividade para estes maciços que provavelmente não deveriam ter ultrapassado 1 ou $2 \mathrm{Ma}$ (ver discussão em ULBRICH, 1984). Isócronas obtidas pelo método $\mathrm{Rb} / \mathrm{Sr}$ reforçam esta argumentação. Os maciços de Poços de Caldas e Passa Quatro, por exemplo, teriam idades mais claramente definidas, condizentes com as expectativas apontadas acima (ver referências em SONOKI \& GARDA, 1988).

Como ainda se dispõe de muito poucas idades avaliadas por métodos de datação mais precisos, partiu-se para uma reavaliação crítica das idades $\mathrm{K} / \mathrm{Ar}$ disponíveis para os maciços alcalinos do Brasil Sul-Oriental e Paraguai Oriental, aplicando-se duas premissas básicas: 1) exame crítico de condições experimentais (mineral e/ou rocha analisados; resultados experimentais), excluindo-se, assim, aquelas idades que não satisfizessem os requisitos mínimos (ver, por ex., DALRYMPLE \& LANPHERE, 1969); 2) o intervalo eruptivo para maciços alcalinos é de, no máximo, alguns poucos Ma, o que faz com que se suspeite das idades que alargam demasiadamente tal intervalo.

A aplicação dessas premissas descarta aproximadamente a metade das idades $\mathrm{K} / \mathrm{Ar}$ conhecidas. Entretanto, a maioria dos maciços apresentam, individualmente, várias idades consideradas aceitáveis, com as quais pode-se calcular uma média aritmética que representaria, ou a idade provável do maciço ou, pelo menos, a idade do "pico" de atividade magmática naquele local.

A comparação entre as médias obtidas para os vários maciços é de particular interesse, pois limitam fortemente os períodos de atividade. Como mostra a Figura 1, são 
destacados apenas quatro "cronogrupos", caracterizados pelas seguintes idades: $133 \mathrm{Ma}, 108$ Ma, 84 Ma e 70-62 Ma. Estes cronogrupos de atividade alcalina relacionam-se, ainda, com feições geológicas importantes. Com o Arco de Ponta Grossa estão associados os cronogrupos de 133, 108 e 84 Ma. Ao longo do cinturão litorâneo São Paulo - Rio de Janeiro são encontrados maciços com idades pertecentes aos cronogrupos de $133 \mathrm{Ma}$ e $84 \mathrm{Ma}$. O cinturão transversal Rio de Janeiro - Minas Gerais, que se estende desde o litoral fluminense até Poços de Caldas, é principalmente definido pelos maciços do cronogrupo de 70-62 Ma (ressalta-se, aqui, que rochas deste cronogrupo datadas recentemente, e.g. BROTZU et al., 1989 e RICCOMINI et al., 1990, forneceram, para os maciços de Itatiaia e Morro Redondo, idades mais antigas do que as obtidas nos primeiros trabalhos nestes maciços e que estão listadas em SONOKI \& GARDA, 1988). Ao longo do cinturão Minas Gerais - Goiás identificam-se os maciços que constituem o cronogrupo de $84 \mathrm{Ma}$. No Paraguai Oriental, encontra-se o cronogrupo de $133 \mathrm{Ma}$.

Fugindo do panorama descrito, destacam-se duas supostas "anomalias etárias". A primeira seria a idade atribuída ao pequeno maciço do Pão de Açúcar (MS) de 242 Ma; a segunda, muito mais importante, é a do conjunto de ocorrências alcalinas localizadas na porção mais ocidental do "rift" de Asunción, próximo da capital paraguaia, para o qual se definiu um padrão etário terciário inferior (BITSCHENE, 1987). Maciços representativos do cronogrupo de 133 Ma situam-se a leste destas ocorrências mais jovens.

Este quadro mostra um fato até certo ponto surpreendente: os cronogrupos repetem-se, pelo menos em parte, por toda a Bacia do Paraná e ao longo de sua borda, sugerindo que a geração e colocação de corpos alcalinos foi fortemente controlada por agentes de natureza provavelmente tectônica (ver também SADOWSKI, 1987), reativados a cada 20 ou $25 \mathrm{Ma}$, ainda que existam fortes dúvidas sobre as idades registradas para o cinturão transversal Rio de Janeiro-Minas Gerais. Descartam-se, assim, as explicações para a geração de seqüências de intrusões causadas, por exemplo, pela passagem de "hot spots", e outras similares, já aventadas na literatura (e.g. HERZ, 1977), para as quais uma seqüência crescente ou decrescente de idades seria esperada e que, neste caso, não se verifica.

\section{AGRADECIMENTOS}

Os autores agradecem o apoio de várias agências financeiras (FINEP, FAPESP, CNPq e CAPES). 


\section{REFERÊNCIAS BIBLIOGRÁFICAS}

ALMEIDA, F.F.M. de (1983) Relações tectônicas das rochas alcalinas mesozóicas da região meridional da Plataforma Sul-Americana. Revista Brasileira de Geociências, 13(3):139158.

AMARAL, G.; BUSHEE, J.; CORDANI, U.G.; KAWASHITA, K.; REYNOLDS, J.H. (1967) Potassium-argon ages of alkaline rocks from Southern Brazil. Geochimica et Cosmochimica Acta, 31(2):117-142.

BITSCHENE, P.R. (1987) Mesozoicher und Kaenozoischer anorogener Magmatismus in Ostparaguay: Arbeiten zur Geologie und Petrologie zweier Alkaliprovinzen. Heidelberg, Ruprecht Karls Universität. 318p. (Tese de Doutoramento, NaturwissenschaftlicheMathematische Gesamtfakultät).

BROTZU, P.; BECCALUVA, L.; CONTE, A.; FONSECA, M.; GARBARINO, C.; GOMES, C.B.; LEONG, R.; MACCIOTTA, G.; MANSUR, R.L.; MELLUSO, L.;MORBIDELLI, L.; RUBERTI, E.; SIGOLO, J.B.; TRAVERSA, G.; VALENÇA, J.G. (1989) Petrological and geochemical studies of alkaline rocks from continental Brazil. 8. The syenitic intrusion of Morro Redondo, RJ. Geochimica Brasiliensis, 3(1):63-80.

DALRYMPLE, G.B. \& LANPHERE, M.A. (1969) Potassium-Argon Dating: principles, techniques and applications to geochronology. San Francisco, Freeman. 258p.

HERZ, N. (1977) Timing of spreading in the South Atlantic: Information from Brazilian alkalic rocks. Geological Society of America Bulletin, 88:101-112.

RICCOMINI, C.; MELO, M.S. de; COUTINHO, J.M.V. (1990) Novo campo de diques de rochas ultrabásicas e efusivas associadas na porção oeste do Estado do Rio de Janeiro. In: WORKSHOP SOBRE DIQUES MÁFICOS DO BRASI, 2., São Paulo, 1990. Boletim especial trabalhos apresentados. São Paulo, IUGS, UNESCO. p.74-86.

SADOWSKI, G.R. (1987) A possible relation between pulses of plataform activation and plate kinetics. Tectonophysics, 143:43-57. 
SHAW, H.R.; JACKSON, E.D.; BARSAR, K.E. (1980) Volcanic periodicity along the Hawaiian - Emperor chain. American Journal of Science, 280-A:667-708.

SONOKI, I.K. \& GARDA, G.M. (1988) Idades K-Ar de rochas alcalinas do Brasil Meridional e Paraguai Oriental: compilação e adaptação às novas constantes de decaimento. Boletim IG-USP, Série Científica, 19:63-85.

ULBRICH, H.H.G.J. (1984) A petrologia, a estrutura e o quimismo de nefelina-sienitos do Maciço Alcalino de Poços de Caldas, MG-SP. São Paulo, 735p. (Tese de Livre Docência, Instituto de Geociências/USP).

ULBRICH, H.H.G.J. \& GOMES, C.B. (1981) Alkaline rocks from continental Brazil. Earth Science Reviews, 17:135-154. 

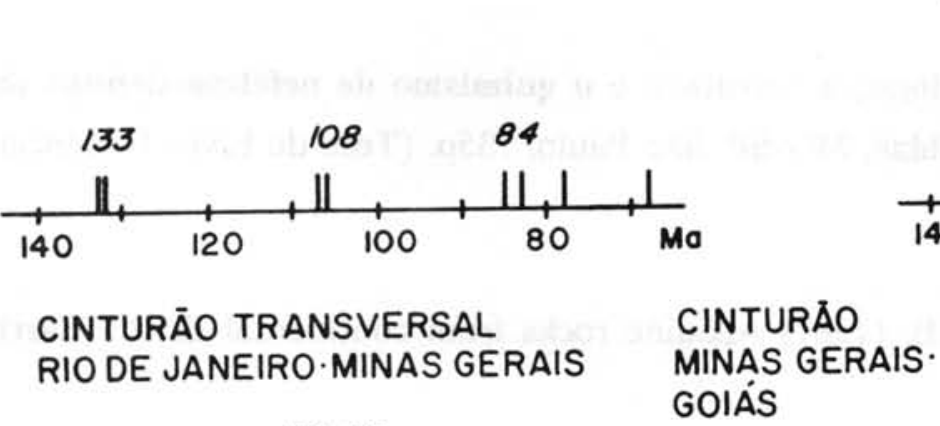

CINTURĀO TRANSVERSAL RIO DE JANEIRO - MINAS GERAIS

CINTURẢO MINAS GERAIS

GOIÁS
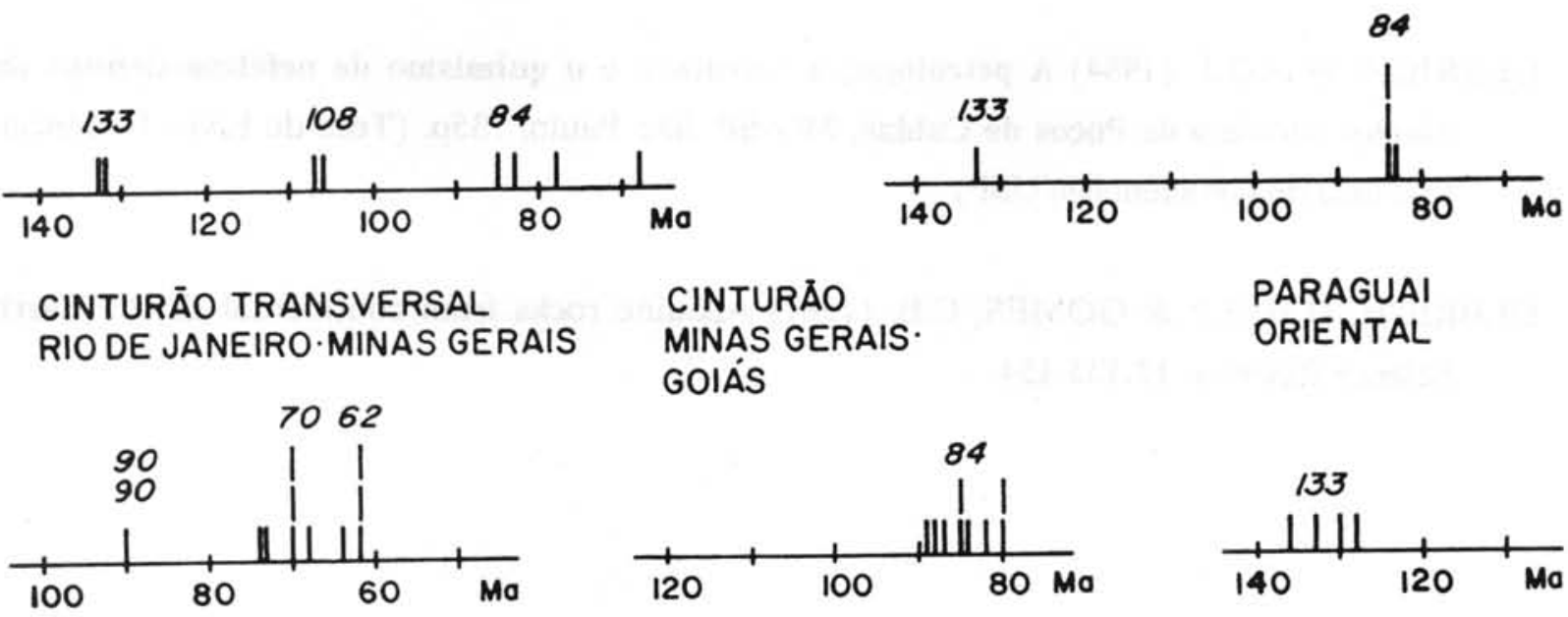

PARAGUAI ORIENTAL

$$
120
$$

100

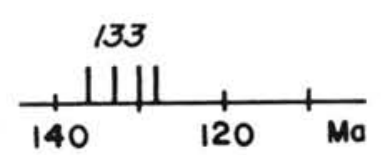

FIGURA 1 - Histograma de "picos" de atividade magmática associada à tectônica de borda da Bacia do Paraná. As barras nos histogramas representam as médias das idades aceitáveis de ocorrências individuais (para localização e descrição das mesmas, ver ULBRICH \& GOMES, 1981 e SONOKI \& GARDA, 1988). Foram considerados os seguintes valores: ARCO DE PONTA GROSSA: 133 (Juquia), 132 (Jacupiranga), 107 (Banhadão), 106 (Itapirapuã), 85 (Tunas), 83 (Cananéia), 78 (Barra do Teixeira) e $68 \mathrm{Ma}$ (Mato Preto). CINTURÃO LITORÂNEO SÃO PAULO - RIO DE JANEIRO: 133 (Itanhaém), 84 (ilhas de Vitória, Búzios e Montão de Trigo) e 83 Ma (São Sebastião). CINTURÃO TRANSVERSAL RIO DE JANEIRO MINAS GERAIS: 90 (idade fornecida pelo método Rb/Sr para Poços de Caldas), 74 (Morro Redondo), 72 (Mendanha), 70 (Itatiaia e Volta Redonda), 68 (Tanguá), 67 (Passa Quatro), 64 (Tinguá) e 62 Ma (Itaúna, Soarinho e Morro de São João). CINTURÃO MINAS GERAIS - GOIÁS: 86 (Tapira), 85 (Catalão), 84 (Santo Antônio da Barra e São Gotardo), 82 (Salitre) e 80 Ma (Pântano). PARAGUAI ORIENTAL: 133 (Sapucai), 132 (Agua-Pety-Porton), 130 (Cerro Charará) e $128 \mathrm{Ma}$ (Cordillera del Ybytyruzú). 